\title{
Common Genetic Polymorphisms in the $A B C B 1$ Gene Are Associated with Risk of Major Depressive Disorder in Male Portuguese Individuals
}

\author{
Marlene Santos, ${ }^{1-3}$ Serafim Carvalho, ${ }^{4,5}$ Luís Lima, ${ }^{2,6,7}$ Augusto Nogueira, \\ Joana Assis, Jorge Mota-Pereira, ${ }^{8}$ Paulo Pimentel, ${ }^{9}$ Dulce Maia, ${ }^{9}$ Diana Correia, \\ Sofia Gomes, ${ }^{4}$ Agostinho Cruz, ${ }^{2}$ and Rui Medeiros ${ }^{1,7,10,11}$
}

\footnotetext{
${ }^{1}$ Molecular Oncology Group, IPO-Porto Research Center (CI-IPOP), Portuguese Institute of Oncology, Porto, Porto, Portugal.

${ }^{2}$ Nucleo de Investigação em Farmácia, Centro de Investigação em Saúde e Ambiente (CISA), School of Allied Health Sciences, Polytechnic Institute of Oporto, Porto, Portugal.

${ }^{3}$ Faculty of Medicine, University of Porto, Porto, Portugal.

${ }^{4}$ Magalhães Lemos Hospital, Porto, Portugal.

${ }^{5}$ Instituto Superior de Ciências da Saúde - Norte, Portugal.

${ }^{6}$ Experimental Pathology and Therapeutics Group, Portuguese Institute of Oncology, Porto, Portugal.

${ }^{7}$ Research Department, Portuguese League Against Cancer (Norte), Porto, Portugal.

${ }^{8}$ Faculty of Psychology, Minho University, Braga, Portugal.

${ }^{9}$ Trás-os-Montes e Alto Douro Hospital Center, Vila Real, Portugal.

${ }^{10}$ Department of Pathology and Molecular Immunology, ICBAS, Abel Salazar Biomedical Sciences Institute, University of Porto, Porto, Portugal.

${ }^{11}$ Health Faculty of University Fernando Pessoa, CEBIMED, Porto, Portugal.
}

Major depressive disorder (MDD) is a highly prevalent disorder, which has been associated with an abnormal response of the hypothalamus-pituitary-adrenal (HPA) axis. Reports have argued that an abnormal HPA axis response can be due to an altered P-Glycoprotein (P-GP) function. This argument suggests that genetic polymorphisms in $A B C B 1$ may have an effect on the HPA axis activity; however, it is still not clear if this influences the risk of MDD. Our study aims to evaluate the effect of ABCB1 C1236T, G2677TA and C3435T genetic polymorphisms on MDD risk in a subset of Portuguese patients. DNA samples from 80 MDD patients and 160 control subjects were genotyped using TaqMan ${ }^{\circledR}$ SNP Genotyping assays. A significant protection for MDD males carrying the $\mathrm{T}$ allele was observed $(\mathrm{C} 1236 \mathrm{~T}$ : odds ratio $(\mathrm{OR})=0.360,95 \%$ confidence interval [CI]: $[0.140-$ 0.950], $p=0.022$; C3435T: OR=0.306, 95\% CI: [0.096-0.980], $p=0.042$; and G2677TA: OR=0.300, 95\% CI: [0.100$0.870], p=0.013)$. Male Portuguese individuals carrying the $1236 \mathrm{~T} / 2677 \mathrm{~T} / 3435 \mathrm{~T}$ haplotype had nearly $70 \%$ less risk of developing MDD (OR=0.313, 95\% CI: [0.118-0.832], $p=0.016$, FDR $p=0.032)$. No significant differences were observed regarding the overall subjects. Our results suggest that genetic variability of the $A B C B 1$ is associated with MDD development in male Portuguese patients. To the best of our knowledge, this is the first report in Caucasian samples to analyze the effect of these $A B C B 1$ genetic polymorphisms on MDD risk.

\section{Introduction}

$\mathbf{M}$ AJOR DEPRESSIVE DISORDER (MDD) is a highly prevalent disorder, with a lifetime risk of $10-25 \%$ in women and $5-12 \%$ in males (Compton et al., 2006). Depression has been associated with an abnormal response of the hypothalamus-pituitary-adrenal (HPA) axis and some authors suggest that the normalization of HPA axis hyperactivity is a crucial step in remission (Holsboer, 2000; Binder et al., 2009). Glucocorticoid hormones, secreted by the adrenal cortex, are potent modulators of neuronal activity and are involved in the maintenance of the basal activity of the HPA axis (Binder et al., 2009). The physiological access of endogenous glucocorticoids to the brain is important for HPA homeostasis. Studies in animal models have proved that the absence of $\mathrm{P}$ Glycoprotein (P-GP) function at the blood-brain barrier (BBB), leads to deep changes in the activity and regulation of the HPA system, suggesting that P-GP may regulate the HPA axis activity (Muller et al., 2003).

P-GP is an ATP-driven efflux pump involved in the pharmacokinetics of P-GP substrate drugs and in the efflux of toxic substances and metabolites, such as glucocorticoids (Kimchi- 
Sarfaty et al., 2007b). This transporter molecule is encoded by the $A B C B 1$ gene (also called MDR1), and is expressed on the epithelial cells of the intestine, canalicular membrane of hepatocytes, and on the endothelial cells of the BBB (Ambudkar et al., 1999).

The overall $A B C B 1$ activity depends on two parameters: the level of expression of the $A B C B 1$ gene, which controls the amount of protein that is synthesized, and the functionality of the P-GP that determines transporter effectiveness and substrate recognition (Hoffmeyer et al., 2000). Several singlenucleotide polymorphisms (SNPs) have been studied in the $A B C B 1$ gene. Among these, polymorphisms in exon 12 (C1236T; rs1128503), in exon 21 (G2677TA; rs2032582), and exon 26 (C3435T; rs1045642) are the ones most reported (Hoffmeyer et al., 2000; Leschziner et al., 2007). Studies regarding the effect of these $A B C B 1$ polymorphisms on P-GP expression and function are not consensual (Borst and Elferink, 2002). Regarding ABCB1 C1236T synonymous polymorphism, some reports found altered drug responses associated with 1236CC (Schaich et al., 2009) and 1236TT variants (Zhang et al., 2008), while others were unable to find any relationship (Estrela Rde et al., 2009). Reports regarding the influence of synonymous C3435T polymorphism are inconclusive (Hodges et al., 2011), and the exact influence of this polymorphism is not known. Several lines of evidence have indicated that this polymorphism affects the expression (Hoffmeyer et al., 2000) and function (Compton et al., 2006) of P-GP, whereas others reported an altered P-GP conformation despite the fact that levels of mRNA and protein were similar (Kimchi-Sarfaty et al., 2007b). Tri-allelic G2677TA nonsynonymous polymorphism has been also widely reported, since its variants are known to induce amino acid modification (Ala893 to Ser/ Thr893) (Leschziner et al., 2007). This polymorphism is also known to affect P-GP functionality (Hodges et al., 2011).

Despite functional studies, investigations focusing on the influence of P-GP polymorphisms and the risk of depression are scarce and have only been conducted in Asian (Qian et al., 2006; Fujii et al., 2012) and Mexican American patients (Dong et al., 2009). This article examines whether common genetic polymorphisms in the $A B C B 1$ gene, previously reported to be associated with antidepressant responses, might be a predictor of risk for MDD in a subset of Portuguese patients.

\section{Materials and Methods}

\section{Patients}

From a total of 92 Portuguese MDD patients followed in a 18-month follow-up study at Magalhães Lemos Hospital, 80 patients agreed to participate in the genetic study (21 males and 59 females), aged 18-60, with a median age of 41.5 years (mean age 40.48; standard deviation 11.06). Participants in the clinical sample were recruited in the outpatient clinic at the Magalhães Lemos Hospital and as part of a broader research on the social-cognitive predictors of pharmacological responses to depression (Carvalho, 2012). Patients with the suspicion of depression were sent to the clinic by their family doctor and those whose clinical interview confirmed the diagnosis of depression were submitted to further evaluation for major depression using the Structured Clinical Interview for DSM Axis I Disorders (SCID-I), and for personality disorders using the Axis II Disorders (SCID-II). Subjects with more than one previous depressive episode, chronic depres- sion, severe physical illness, psychiatric disorders with psychotic symptoms, substance dependence, or personality disorders were excluded from the study. Age- and gendermatched healthy control individuals were recruited from the same city. These healthy controls consisted of 160 individuals (42 males and 118 females) with median age of 41 years (mean age 40.48; standard deviation 11.08), collected among the blood donors of the Portuguese Institute of Oncology-Porto. The blood donors completed a health questionnaire, and were interviewed by a physician about their medications and possible chronic illnesses. The study was approved by the ethics committee of Magalhães Lemos Hospital. Written informed consent according to The Code of Ethics of the World Medical Association (Declaration of Helsinki) was obtained from each individual after explanation of the study.

\section{Sample collection and DNA extraction}

Peripheral blood samples were collected following the standard venipuncture technique in EDTA-containing tubes, and the genomic DNA was extracted from the whole blood with a commercial kit (E.Z.N.A.-Omega Bio-tek, Norcross, USA), according to the manufacturer's instructions and stored at $-20^{\circ} \mathrm{C}$.

\section{C1236T, G2677TA, C3435T ABCB1 polymorphism analysis}

The C1236T, G2677TA, C3435T ABCB1 polymorphism analysis was carried using TaqMan ${ }^{\circledR}$ SNP Genotyping Assays C__7586662_10; C_11711720C_30 and C_11711720D_40; C__7586657_20, respectively (Applied Biosystems, Foster City, CA). Reactions were performed on an Applied Biosystems 7300 Real Time PCR System (Applied Biosystems) with a $5 \mu \mathrm{L}$ final volume mixture containing $1 \times$ TaqMan Genotyping Master Mix (Applied Biosystems), $900 \mathrm{nM}$ of each primer, $200 \mathrm{nM}$ of probes labeled with either FAM or VIC, and $10 \mathrm{ng}$ of extracted DNA. Thermal cycling conditions were $10 \mathrm{~min}$ at $95^{\circ} \mathrm{C}$ followed by 45 cycles (or 50 cycles for G2677TA) of $15 \mathrm{~s}$ at $95^{\circ} \mathrm{C}$ and $1 \mathrm{~min}$ at $60^{\circ} \mathrm{C}$. Allelic discrimination was performed by measuring endpoint fluorescence using an ABI PRISM ${ }^{\circledR}$ 7300 Sequence Detection System (Applied Biosystems). Genotyping data were read blind to the clinical course of illness and, in case of ambiguous genotypic data, experiments were repeated for determining the genotype of every individual.

\section{Statistical analysis}

Data preparation and analysis were carried out using the computer software PAWS Statistics 18 (release 18.0.0) and Epi Info (version 6.04a). A 5\% level of significance was used in the chi-square $\left(\chi^{2}\right)$ analysis to compare the categorical variables. The odds ratio (OR) and 95\% confidence interval (CI) were calculated as a measure of association between genotypes and MDD risk. The Fisher's exact test was used for tables containing cells, where values are less than five individuals. The Hardy-Weinberg equilibrium was tested by a $\chi^{2}$ test to compare the observed versus the expected genotype frequencies. Measures of linkage disequilibrium (LD), represented as $D^{\prime}$ and $r^{2}$, were calculated from the haplotype frequency using the expectation-maximization (EM) algorithm with SNP \& Variation Suite 7 free trial (Golden Helix) software. In addition, to correct for multiple comparison testing, adjusted $p$-values were determined using the false 
discovery rate (FDR) method. A posteriori power analysis was performed using Quanto software (version 1.0; http:// hydra.usc.edu/gxe) with input of the following variables: case-control study design, significance level $(\alpha)<0.05$ (two sided), model of inheritance $=\log$ additive, minor allele frequency $=0.406$, and genetic effect for OR $(\geq 1.75$ and $\leq 0.55$ ). This study achieved a statistical power of $80 \%$ for the minor allele of $A B C B 1$ C1236T, which exhibited the lowest allele frequency among the three polymorphisms.

\section{Results}

\section{Allele and genotype frequencies of ABCB1 gene}

The genotype and allele frequencies of the ABCB1 C1236T, C3435T and C2677TA polymorphisms are shown in Table 1. No significant deviations from the Hardy-Weinberg equilibrium proportions were observed both in controls and cases (Table 1). LD pairwise analysis revealed a strong LD between C1236T and G2677TA $\left(D^{\prime}=0.88, r^{2}=0.75\right)$ and C3435T and G2677TA ( $D^{\prime}$ 0.83, $\left.p=0.59\right)$, while C1236T and C3435T loci were in moderate $\operatorname{LD}\left(D^{\prime}=0.67, r^{2}=0.40\right)$.

\section{Allele and genotype association with MDD risk}

To estimate the influence of $A B C B 1$ polymorphisms in the development of MDD, allele and genotype frequencies were compared between MDD patients and controls. Our results did not reveal any statistically significant association (Table 1). However, a tendency of a lower MDD risk was verified for 1236TT genotype carriers (OR $=0.699$; 95\% CI: [0.309-1.582]; $p=0.390)$. Similar results were found for individuals carrying the 2677TT variant (OR $=0.615 ; 95 \%$ CI: [0.248-1.525]; $p=0.291)$.
Nevertheless, when data were stratified according to gender, a significant association was verified among male patients (Table 2). Carriers of the variant T allele in C1236T, C3435T, and G2677TA polymorphisms had lower risk of developing $\mathrm{MDD}(\mathrm{OR}=0.360,95 \% \mathrm{CI}$ : [0.140-0.950], $p=0.022$; $\mathrm{OR}=0.306,95 \% \mathrm{CI}$ : [0.096-0.980], $p=0.042 ; \mathrm{OR}=0.300,95 \%$ CI: [0.100-0.870], $p=0.013$, respectively).

\section{Haplotype association with MDD risk}

To estimate the combined influence of $A B C B 1$ polymorphisms in the risk of MDD development, haplotype analysis was carried out. A total of seven different haplotypes were identified using the SVS software (Table 3). Although haplotype analysis did not reveal any significant association with MDD diagnosis regarding the overall subjects, TTT haplotype was associated to a lower risk of MDD development in male subjects (OR $=0.313,95 \% \mathrm{CI}$ : [0.118-0.832], $p=0.016)$. The association remained statistically significant after multiple comparisons adjustment (FDR $p=0.032$ ).

\section{Comparison of ABCB1 genotype frequencies with reports from the literature}

To verify if our control subjects are similar to other Caucasian populations, we compared the frequencies of the genetic polymorphisms evaluated in this study with the observed frequencies in the control samples from other reports. Genotype and allele frequencies of our controls were not different from what is reported in the literature, regarding the Portuguese population $\left(C 1236 \mathrm{~T}: \chi^{2}=4.81, \mathrm{DF}=2, p=0.09 ; \mathrm{G} 2677 \mathrm{TA}\right.$ : $\left.\chi^{2}=4.84, \mathrm{DF}=2, p=0.089 ; C 3435 T: \chi^{2}=4.79 ; \mathrm{DF}=2 ; p=0.091\right)$.

Table 1. Allele and Genotype Frequencies of ABCB1 Polymorphisms and Risk for Major Depressive Disorder

\begin{tabular}{|c|c|c|c|c|c|c|c|c|c|c|}
\hline \multirow[b]{2}{*}{ SNP } & \multirow[b]{2}{*}{ Alleles/genotypes } & \multicolumn{2}{|c|}{ Controls } & \multicolumn{2}{|c|}{ Cases } & \multicolumn{2}{|c|}{ HWE $\mathrm{p}$} & \multirow[b]{2}{*}{$O R$} & \multirow[b]{2}{*}{$95 \% C I$} & \multirow[b]{2}{*}{$\mathrm{p}$-Value } \\
\hline & & $\mathrm{N}$ & $\%$ & $\mathrm{~N}$ & $\%$ & Controls & Cases & & & \\
\hline \multirow[t]{6}{*}{ C1236T } & $\mathrm{C}$ & 190 & 59.4 & 101 & 63.0 & \multirow[t]{6}{*}{0.395} & \multirow[t]{6}{*}{0.953} & & Referent & \\
\hline & $\mathrm{T}$ & 130 & 40.6 & 59 & 37.0 & & & 0.850 & [0.570-1.290] & 0.428 \\
\hline & $\mathrm{CC}$ & 59 & 36.9 & 32 & 40.0 & & & & Referent & \\
\hline & CT & 72 & 45.0 & 37 & 46.2 & & & 0.947 & [0.528-1.701] & 0.857 \\
\hline & TT & 29 & 18.1 & 11 & 13.8 & & & 0.699 & [0.309-1.582] & 0.390 \\
\hline & $\mathrm{T}$ Carrier & 101 & 63.1 & 48 & 60.0 & & & 0.638 & [0.505-1.520] & 0.638 \\
\hline \multirow[t]{6}{*}{ C3435T } & C & 185 & 57.8 & 91 & 56.9 & \multirow[t]{6}{*}{0.413} & \multirow[t]{6}{*}{0.956} & & Referent & \\
\hline & $\mathrm{T}$ & 135 & 42.2 & 69 & 43.1 & & & 1.040 & [0.700-1.550] & 0.845 \\
\hline & $\mathrm{CC}$ & 56 & 35.0 & 26 & 32.5 & & & & Referent & \\
\hline & CT & 73 & 45.6 & 39 & 48.8 & & & 1.151 & [0.628-2.110] & 0.650 \\
\hline & $\mathrm{TT}$ & 31 & 19.4 & 15 & 18.8 & & & 1.042 & [0.481-2.256] & 0.916 \\
\hline & $\mathrm{T}$ Carrier & 104 & 65.0 & 54 & 67.5 & & & 1.118 & [0.633-1.977] & 0.700 \\
\hline \multirow[t]{10}{*}{ G2677TA } & G & 195 & 60.9 & 101 & 63.1 & \multirow[t]{10}{*}{0.891} & \multirow[t]{10}{*}{0.953} & & Referent & \\
\hline & $\mathrm{T}$ & 120 & 37.5 & 55 & 34.4 & & & 0.880 & [0.580-1.350] & 0.548 \\
\hline & A & 5 & 1.6 & 4 & 2.5 & & & 1.540 & [0.340-6.800] & $0.500^{*}$ \\
\hline & GG & 59 & 36.9 & 32 & 40.0 & & & & Referent & \\
\hline & GT & 72 & 45.0 & 36 & 45.0 & & & 0.922 & [0.512-1.659] & 0.786 \\
\hline & GA & 5 & 3.1 & 1 & 1.2 & & & 0.369 & [0.041-3.294] & $0.661^{*}$ \\
\hline & TT & 24 & 15.0 & 8 & 10.0 & & & 0.615 & [0.248-1.525] & 0.291 \\
\hline & $\mathrm{AA}$ & ND & - & ND & - & & & $* *$ & ** & $* *$ \\
\hline & TA & ND & - & 3 & 3.8 & & & $* *$ & $* *$ & $0.049^{*}$ \\
\hline & Variant Carrier & 101 & 63.1 & 48 & 60.0 & & & 0.876 & [0.505-1.520] & 0.638 \\
\hline
\end{tabular}

Bold values indicate $p<0.05$.

*One cell count is less than 5, Fisher's exact test was used.

** One cell count is 0 , unable to calculate OR.

OR, odds ratio; ND, not detected; HWE, Hardy-Weinberg equilibrium; CI, confidence interval; SNP, single-nucleotide polymorphisms. 
Table 2. Allele and Genotype Frequencies of ABCB1 Polymorphisms and Risk For Major Depressive Disorder in MALes

\begin{tabular}{|c|c|c|c|c|c|c|c|c|c|c|}
\hline \multirow[b]{2}{*}{ SNP } & \multirow[b]{2}{*}{ Alleles/genotypes } & \multicolumn{2}{|c|}{ Controls } & \multicolumn{2}{|c|}{ Cases } & \multicolumn{2}{|c|}{ HWE $\mathrm{p}$} & \multirow[b]{2}{*}{ OR } & \multirow[b]{2}{*}{$95 \% \mathrm{CI}$} & \multirow[b]{2}{*}{$\mathrm{p}$-Value } \\
\hline & & $\mathrm{N}$ & $\%$ & $\mathrm{~N}$ & $\%$ & Controls & Cases & & & \\
\hline \multirow[t]{6}{*}{ C1236T } & $\mathrm{C}$ & 51 & 60.7 & 34 & 81.0 & \multirow[t]{6}{*}{0.755} & \multirow[t]{6}{*}{0.736} & & Referent & \\
\hline & $\mathrm{T}$ & 33 & 39.3 & 8 & 19.0 & & & 0.360 & {$[0.140-0.950]$} & 0.022 \\
\hline & $\mathrm{CC}$ & 15 & 35.7 & 14 & 66.7 & & & & Referent & \\
\hline & $\mathrm{CT}$ & 21 & 50.0 & 6 & 28.6 & & & 0.306 & [0.096-0.980] & 0.042 \\
\hline & $\mathrm{TT}$ & 6 & 14.3 & 1 & 4.8 & & & 0.179 & [0.019-1.675] & $0.200^{*}$ \\
\hline & $\mathrm{T}$ Carrier & 27 & 64.3 & 7 & 33.3 & & & 0.278 & [0.092-0.839] & 0.020 \\
\hline \multirow[t]{6}{*}{ C3435T } & $\mathrm{C}$ & 48 & 57.1 & 33 & 78.6 & \multirow[t]{6}{*}{0.418} & \multirow[t]{6}{*}{0.211} & & Referent & \\
\hline & $\mathrm{T}$ & 36 & 42.9 & 9 & 21.4 & & & 0.36 & [0.140-0.920] & 0.018 \\
\hline & $\mathrm{CC}$ & 15 & 35.7 & 12 & 57.1 & & & & Referent & \\
\hline & $\mathrm{CT}$ & 18 & 42.9 & 9 & 42.9 & & & 0.625 & [0.207-1.883] & 0.402 \\
\hline & $\mathrm{TT}$ & 9 & 21.4 & ND & - & & & $* *$ & $* *$ & $0.016^{*}$ \\
\hline & $\mathrm{T}$ Carrier & 27 & 64.3 & 9 & 42.9 & & & 0.417 & [0.143-1.215] & 0.105 \\
\hline \multirow[t]{10}{*}{ G2677TA } & $\mathrm{G}$ & 53 & 63.1 & 35 & 81.0 & \multirow[t]{10}{*}{0.633} & \multirow[t]{10}{*}{0.359} & & Referent & \\
\hline & $\mathrm{T}$ & 30 & 35.7 & 6 & 14.3 & & & 0.300 & {$[0.100-0.870]$} & 0.013 \\
\hline & $\mathrm{A}$ & 1 & 1.2 & 1 & 2.4 & & & 1.510 & [0.000-57.66] & $1.000^{*}$ \\
\hline & GG & 16 & 38.1 & 14 & 66.7 & & & & Referent & \\
\hline & GT & 20 & 47.6 & 6 & 28.6 & & & 0.343 & [0.107-1.094] & 0.066 \\
\hline & GA & 1 & 2.4 & 1 & 4.8 & & & 1.143 & [0.065-20.018] & $1.000^{*}$ \\
\hline & $\mathrm{TT}$ & 5 & 11.9 & ND & - & & & $* *$ & $* *$ & $0.069^{*}$ \\
\hline & AA & ND & - & ND & - & & & $* *$ & $* *$ & $* *$ \\
\hline & $\mathrm{TA}$ & ND & - & ND & - & & & $* *$ & $* *$ & $* *$ \\
\hline & Variant Carrier & 20 & 47.6 & 6 & 28.6 & & & 0.308 & [0.102-0.925] & 0.032 \\
\hline
\end{tabular}

Bold values indicate $p<0.05$.

*One cell count is less than 5, Fisher's exact test was used.

**One cell count is 0 , unable to calculate OR.

Genotype frequency distribution of the C1236T SNP in our study group was not significantly different than other Caucasian populations, such as Czech, French, German, and Hungarian. However, significant differences were found with other ethnic groups, such as Chinese, Indian, Japanese, Turkish, and Malay populations (Table 4). Similar results were found for G2677TA (Table 4). Concerning C3435T polymorphism, no significant differences were found between our study and the Mediterranean populations. However, significant differences were found for other Caucasian populations such as British, German, Hungarian, Czech, and Polish (Table 4).

\section{Discussion}

We investigated three common SNPs in the $A B C B 1$ gene (C1236T, G2677TA and C3435T) in a subset of Portuguese patients with MDD. To the best of our knowledge, no reports have been published in Caucasian populations regarding the effect of these $A B C B 1$ genetic polymorphisms on MDD risk.

Table 3. Haplotype Frequencies Derived from ABCB1 C1236T, G2677TA and C3435T Polymorphisms in Control Subjects and in Patients with Major Depressive Disorder

\begin{tabular}{|c|c|c|c|c|c|c|}
\hline Haplotype & Controls frequency & Cases frequency & OR & $95 \% \mathrm{CI}$ & $\mathrm{p}$-Value & FDR p-Value \\
\hline \multicolumn{7}{|l|}{ CGC vs. Non CGC } \\
\hline Overall & 0.481 & 0.514 & 1.153 & [0.786-1.691] & 0.468 & 0.818 \\
\hline Males & 0.511 & 0.735 & 2.769 & [1.205-6.363] & 0.015 & 0.058 \\
\hline \multicolumn{7}{|l|}{ TTT vs Non TTT } \\
\hline Overall & 0.316 & 0.327 & 1.060 & [0.705-1.593] & 0.778 & 0.908 \\
\hline Males & 0.345 & 0.142 & 0.313 & [0.118-0.832] & 0.016 & 0.032 \\
\hline \multicolumn{7}{|l|}{ CGT vs. Non CGT } \\
\hline Overall & 0.072 & 0.082 & 1.160 & [0.573-2.349] & 0.679 & 0.950 \\
\hline Males & 0.071 & 0.051 & 0.692 & [0.138-3.468] & 0.653 & 0.870 \\
\hline \multicolumn{7}{|l|}{ TGC vs. Non TGC } \\
\hline Overall & 0.049 & 0.031 & 0.627 & [0.225-1.749] & 0.368 & 0.860 \\
\hline Males & 0.048 & 0.048 & 1.000 & [0.175-5.699] & 1.000 & 1.000 \\
\hline TTC vs. Non TTC & 0.034 & 0.007 & 0.196 & [0.027-1.398] & 0.071 & 0.497 \\
\hline CTT vs. Non CTT & 0.022 & 0.006 & 0.282 & [0.034-2.314] & 0.209 & 0.731 \\
\hline CAC vs. Non CAC & 0.011 & 0.013 & 1.241 & [0.219-7.021] & 0.807 & 0.807 \\
\hline
\end{tabular}

Bold values indicate $p<0.05$.

FDR, false discovery rate. 
Table 4. Allele and Genotype Frequencies for the ABCB1 C1236T, G2677TA, and C3435T SNPs in Portuguese Subjects and in Other European and Asian Populations

\begin{tabular}{|c|c|c|c|c|c|c|c|c|c|}
\hline & Population & $N$ & $T \%$ & $C C$ & $\%(N)$ & $C T \%(N)$ & $\mathrm{TT} \%(N)$ & $\mathrm{p}$-Value & Ref. \\
\hline \multirow[t]{14}{*}{ C1236T } & Portuguese & 160 & 40.6 & \multicolumn{2}{|c|}{$36.9(59)$} & $45.0(72)$ & $18.1(29)$ & - & This study \\
\hline & Portuguese & 100 & 46.0 & \multicolumn{2}{|c|}{$25.0(25)$} & $58.0(58)$ & $17.0(17)$ & 0.090 & (Correia et al., 2009) \\
\hline & French & 223 & 42.0 & \multicolumn{2}{|c|}{$33.0(74)$} & $49.0(110)$ & $17.5(39)$ & 0.686 & (Jeannesson et al., 2007) \\
\hline & German & 461 & 41.0 & \multicolumn{2}{|c|}{$34.3(158)$} & $49.2(227)$ & $16.5(76)$ & 0.650 & (Cascorbi et al., 2001) \\
\hline & Hungarian & 503 & 44.3 & \multicolumn{2}{|c|}{$33.2(167)$} & $44.9(226)$ & $21.9(110)$ & 0.524 & (Sipeky et al., 2011) \\
\hline & Czech & 189 & 44.5 & \multicolumn{2}{|c|}{$31.7(60)$} & $47.1(89)$ & $21.2(40)$ & 0.561 & (Pechandova et al., 2006) \\
\hline & Polish & 139 & 41.4 & \multicolumn{2}{|c|}{35.3 (49) } & $46.8(65)$ & $18.0(25)$ & 0.949 & (Tan et al., 2004) \\
\hline & Chinese & 206 & 63.8 & \multicolumn{2}{|c|}{$15.5(32)$} & $41.3(85)$ & $43.2(89)$ & $<0.001$ & (Tan et al., 2005) \\
\hline & Indian & 87 & 67.2 & \multicolumn{2}{|c|}{$13.8(12)$} & 37.9 (33) & $48.3(42)$ & $<0.001$ & (Chowbay et al., 2003) \\
\hline & Japanese & 1100 & 60.0 & \multicolumn{2}{|c|}{$16.3(179)$} & $46.7(514)$ & $37.0(407)$ & $<0.001$ & (Fujii et al., 2012) \\
\hline & Malay & 92 & 62.5 & \multicolumn{2}{|c|}{$12.0(11)$} & $44.6(41)$ & $43.5(40)$ & $<0.001$ & (Chowbay et al., 2003) \\
\hline & Korean & 232 & 61.9 & 11.6 & $(27)$ & $53.0(123)$ & $35.4(82)$ & $<0.001$ & (Lee et al., 2005) \\
\hline & Turkish & 100 & 54.5 & 20.0 & $(20)$ & $51.0(51)$ & $29.0(29)$ & 0.009 & (Gumus-Akay et al., 2008) \\
\hline & Population & $N$ & $T \%$ & & $\%(N)$ & $C T \%(N)$ & $\mathrm{TT} \%(N)$ & $\mathrm{p}$-Value & Ref. \\
\hline C3435T & Portuguese & 160 & 42.2 & 35. & $0(56)$ & $45.6(73)$ & $19.4(31)$ & - & This study \\
\hline & Portuguese & 100 & 57.0 & 22. & $8(23)$ & $57.9(58)$ & $19.3(19)$ & 0.091 & (Correia et al., 2009) \\
\hline & Spanish & 408 & 48.0 & 26. & $0(106)$ & $52.0(212)$ & $22.0(90)$ & 0.101 & (Bernal et al., 2003) \\
\hline & French & 222 & 46.0 & 28. & $0(61)$ & $52.0(116)$ & $20.0(45)$ & 0.275 & (Jeannesson et al., 2007) \\
\hline & Italian & 450 & 47.8 & 25. & $6(115)$ & $53.3(240)$ & $21.1(95)$ & 0.071 & (Palmieri et al., 2005) \\
\hline & British & 280 & 53.9 & 21. & $8(61)$ & $48.6(136)$ & $29.6(83)$ & 0.004 & (Onnie et al., 2006) \\
\hline & German & 461 & 53.9 & 20. & $8(96)$ & $50.5(233)$ & $28.6(132)$ & $<0.001$ & (Cascorbi et al., 2001) \\
\hline & Hungarian & 503 & 52.7 & & $3(112)$ & $50.1(252)$ & $27.6(139)$ & 0.003 & (Sipeky et al., 2011) \\
\hline & Czech & 189 & 56.5 & 21. & $2(40)$ & $44.9(85)$ & $33.9(64)$ & $<0.001$ & (Pechandova et al., 2006) \\
\hline & Polish & 173 & 52.2 & 21. & $6(30)$ & $52.5(73)$ & $25.9(36)$ & 0.021 & (Tan et al., 2004) \\
\hline & Chinese & 206 & 34.7 & 42. & $2(87)$ & $46.1(95)$ & $11.7(24)$ & 0.091 & (Tan et al., 2005) \\
\hline & Indian & 87 & 62.3 & 18. & $4(16)$ & $36.8(32)$ & $44.8(39)$ & $<0.001$ & (Chowbay et al., 2003) \\
\hline & Japanese & 1100 & 40.0 & 35. & $0(386)$ & $50.0(552)$ & $15.0(162)$ & 0.279 & (Fujii et al., 2012) \\
\hline & Population & $N$ & $A \%$ & $T \%$ & $G G \%(N)$ & $\begin{array}{c}G T+ \\
G A \%(N)\end{array}$ & $\begin{array}{l}T T+T A+ \\
A A \%(N)\end{array}$ & $\mathrm{p}$-Value & Ref. \\
\hline G2677TA & Portuguese & 160 & 1.6 & 37.5 & $36.9(59)$ & $48.1(77)$ & $15.0(24)$ & - & This \\
\hline & Portuguese & 100 & NE & 47.5 & $31.0(31)$ & $43.0(43)$ & $26.0(26)$ & 0.089 & (Cavaco et al., 2003) \\
\hline & French & 225 & 45. & & $28.4(64)$ & $52.4(118)$ & $19.1(43)$ & 0.189 & (Jeannesson et al., 2007) \\
\hline & Italian & 450 & 2.0 & 43.6 & $28.0(126)$ & $55.1(248)$ & $16.9(76)$ & 0.111 & (Palmieri et al., 2005) \\
\hline & British & 285 & 2.5 & 39.6 & $33.0(94)$ & $49.8(142)$ & $17.2(49)$ & 0.601 & (Onnie et al., 2006) \\
\hline & German & 461 & 1.9 & 41.6 & $31.0(143)$ & $51.2(236)$ & $17.8(82)$ & 0.365 & (Cascorbi et al., 2001) \\
\hline & Hungarian & 503 & 1.1 & 44.1 & $30.6(154)$ & $48.3(243)$ & $21.1(106)$ & 0.152 & (Sipeky et al., 2011) \\
\hline & Czech & 189 & 0.5 & 46.0 & $29.6(56)$ & $48.1(91)$ & $22.2(42)$ & 0.152 & (Pechandova et al., 2006) \\
\hline & Polish & 139 & 1.1 & 41.4 & $33.8(47)$ & $47.5(66)$ & $18.7(26)$ & 0.668 & (Tan et al., 2004) \\
\hline & Chinese & 206 & 11.4 & 36.4 & $27.7(57)$ & $49.0(101)$ & $23.3(48)$ & 0.062 & (Tan et al., 2005) \\
\hline & Indian & 87 & 6.9 & 59.8 & $13.8(12)$ & $39.1(34)$ & $47.1(41)$ & $<0.001$ & (Chowbay et al., 2003) \\
\hline & Japanese & 1100 & 18.0 & 39.0 & $17.5(193)$ & $50.9(560)$ & 31.5 (347) & $<0.001$ & (Fujii et al., 2012) \\
\hline & Korean & 632 & 17.1 & 39.1 & $19.1(121)$ & $49.4(312)$ & 31.5 (199) & $<0.001$ & (Lee et al., 2005) \\
\hline & Turkish & 70 & ND & 47.0 & $30.0(21)$ & $44.3(31)$ & $25.7(18)$ & 0.144 & (Sapmaz et al., 2008) \\
\hline
\end{tabular}

Bold values indicate $p<0.05$.

Furthermore, the previous reports associating the risk of MDD and functional polymorphisms in $A B C B 1$ were conducted in Asian populations, and have only evaluated the effect of C1236T and C3435T polymorphisms in haplotype analysis. We included in the study, a third polymorphism in the $A B C B 1$ haplotype analysis, the triallelic G2677TA functional genetic polymorphism.

We demonstrated a significant protection for MDD only in males carrying the $\mathrm{T}$ allele in the evaluated polymorphisms. Moreover, the haplotype analysis revealed that male individuals carrying the TTT haplotype have nearly $70 \%$ less risk of developing MDD. Overall, the case-control analysis showed no association between the risk of MDD and the presence of a specific allele, genotype, or haplotype. Our results seem to indicate that the influence of $A B C B 1$ functional polymorphism in the risk of MDD is gender specific.

Although several reports addressed the influence of these $A B C B 1$ genetic polymorphisms in antidepressant responses, only two studies have evaluated the association of these common polymorphisms in the $A B C B 1$ gene and the risk of depression (Qian et al., 2006; Fujii et al., 2012). Fujii et al. (2012) observed, in a large group of Japanese subjects that, carriers of the 3435T allele or 1236T-3435T haplotype were more common in patients than in controls, suggesting that C3435T may 
have a role in MDD development risk. However, regarding the triallelic SNP, G2677TA, the authors did not find any significant differences in allelic and genotypic frequencies between cases and controls. In another study, Qian et al. (2006) evaluated the effect of C3435T and G2677TA polymorphisms in mood disorders, including depression. No significant association between this C3435T polymorphism and the risk of developing mood disorder was found, but a higher frequency of 2677A was observed in patients with mood disorders than in controls $(p<0.05)$ (Qian et al., 2006). The putative reasons for these discrepancies are widely discussed in the article by Fujii et al. (2012), and are related to the sample size and the heterogeneity of the patients used in the Qian et al. (2006) study.

We observed that the TT genotype in C3435T was less common in male cases than in controls and this points to a different direction when compared to the reports of Fujii et al. (2012) and Qian et al. (2006). These nonconcordant results may be explained by two lines of evidence. First, both studies evaluated MDD risk in Asian subjects. The genetic variability of the $A B C B 1$ polymorphisms is known to diverge among ethnic groups (Ameyaw et al., 2001; Sipeky et al., 2011), as shown in Table 4. Second, no stratification on gender was present in these studies. As proposed by Becker et al., (2009) gender stratification is essential when evaluating the effect of these $A B C B 1$ polymorphisms, since they are found to be associated with the cholesterol-lowering effect of simvastatin only in males. Additionally, it has been proposed by several authors that different susceptibility of depression is under the major influence of gender (Unschuld et al., 2010).

Haplotype analysis in $A B C B 1$ polymorphisms, rather than a single SNP, may provide an advantage in the diagnosis of complex diseases, such as MDD. In fact, there are reports of significant correlations found using ABCB1 1236T-2677T$3435 \mathrm{~T}$ haplotype analysis and lack of association when each SNP was analyzed separately (Potocnik et al., 2004; KimchiSarfaty et al., 2007a). We observed that the ABCB1 1236T2677T-3435T haplotype presents a protective effect since the male carriers of this profile have a lower risk of developing MDD (OR $=0.313,95 \%$ CI: [0.118-0.832], $p=0.016)$. Clinical studies have shown that the 1236T-2677T-3435T haplotype is also associated with reduced P-GP activity (Salama et al., 2006). Indeed, recombinant cells expressing ABCB1 1236T2677T-3435T variants displayed only $0-22.7 \%$ transporter activity, which suggests that this haplotype significantly reduces P-GP functionality in vitro, losing about $80 \%-100 \%$ of its efflux capability (Salama et al., 2006). Although some authors defend that the lack of P-GP function could lead to the accumulation of deleterious substances, such as neurotoxins, and represent a risk of MDD development (Fujii et al., 2012), we hypothesized that male carriers of the 1236T-2677T-3435T haplotype may have a less active transporter and this might be protective for the risk of MDD. P-GP is known to in vivo regulate brain access of endogenous steroid hormones (Uhr et al., 2002; Binder et al., 2009). In normal subjects, the HPA axis is regulated by a negative feedback control, whereby glucocorticoids secreted from the adrenal gland suppress the hypothalamus to secret the corticotrophin releasing hormone (CRH) and arginine-vasopressin, which per se limits the release of corticotrophin (ACTH) from the anterior pituitary, and thus promotes less glucocorticoid release from adrenal glands (O'Brien et al., 2012). In depressed patients, this negative feedback control is impaired and patients display HPA axis hyperactivity, evident by an increased cortisol concentration in serum, urine, and the cerebrospinal fluid (Holsboer, 2000; Pariante and Miller, 2001).

Our hypothesis is that the putative lower P-GP function, found in carriers of the 1236T/2677T/3435T haplotype, may restrain HPA system activation after stressful events, and induce a chronically increased negative feedback at the hypothalamic level due to an enhanced penetration of glucocorticoid hormones into the central nervous system, and promote a less active HPA response under stress conditions. Interestingly, in vivo studies using abcblab (-/ -) mice mutants prove that the absence of P-GP leads to an increased penetration of corticosteroid hormones in the central nervous system, which in turn, enhanced central negative feedback inhibition of stress hormone secretion, with lower plasma ACTH levels in both at basal and under stress conditions (Muller et al., 2003). Moreover, antidepressants have also inhibited P-GP in vitro, and decreased the HPA axis activity in vivo, leading to the hypothesis that antidepressants inhibit P-GP at the BBB and increase glucocorticoid access to the brain (Yau et al., 2007).

The gender-specific trait of our results can be explained by the differential expression of P-GP in male and female (Suzuki et al., 2006; Bebawy and Chetty, 2009). Sex hormones can regulate the expression of P-GP in systemic organs, contributing to the differences observed in metabolic disposition (Compton et al., 2006). Interestingly, the male androgens suppress P-GP expression and function, contrary to what is reported for the female sex hormones, but the precise mechanism for testosterone repression of P-GP expression remains undefined (Suzuki et al., 2006). Moreover, a distinct HPA axis activation among male and female might explain our results. Binder et al., (2009) observed a normalization of HPA axis reactivity, illustrated by the dexamethasone-resistant test, only among male patients with remission of depressive symptoms. Another report showed that knockdown of glucocorticoid receptors in the medial prefrontal cortex, hippocampus, and basolateral amygdala induces depression-like behaviors in male mice, but not in females (Solomon et al., 2012). This author suggests that this mechanism for development of mood disorders holds only in males and provable symptoms of depression are mediated by an alternative brain circuitry and / or different molecular substrates in comparison with female gender individuals (Solomon et al., 2012). Additionally, several reports in the literature regarding depression and antidepressant responses, point out for differences among male and female patients (Schaich et al., 2009; Kurita et al., 2012). The absence of a significant association in women found in our study does not exclude the fact that genetic variation in $A B C B 1$ does affect the risk of MDD development in women, but the effect is most likely weaker in women than in males.

The main limitation of our study is the relatively low number of subjects genotyped. Major concerns of small sample studies are false-positive results and over-estimation of magnitude association. To exclude false-positive results, FDR correction was included for multiple comparisons, and our results remain statistically significant for the TTT haplotype. In this study, high magnitude associations (OR $\geq 1.75$ and $\leq 0.55$ ) are detected with an $80 \%$ statistical power, like the one we found for the male TTT haplotype. However, it is possible that small effects are not detected with our sample. Control selection bias was excluded by comparing genotypic 
frequencies of our controls and other southern Caucasian samples, including Portuguese. Although our study was the first to analyze the influence of $A B C B 1$ C1236T, C3435T and G2677TA polymorphisms in a Caucasian subset of MDD patients, independent association studies with larger sample sizes are needed to confirm the influence of these SNPs in MDD development risk.

In conclusion, this article adds clinical evidence that genetic variability of the $A B C B 1$ is associated with MDD in males, and that this may influence the HPA system activity, through a less active P-GP. The observed sex differences in $A B C B 1$ polymorphisms and risk of MDD may explain a gender dimorphic sensitivity of the HPA axis and hypothetically reflect a gender-specific pathophysiology of depression.

\section{Acknowledgments}

This work was supported by a grant from the AstraZeneca Foundation. The authors would like to thank the contribution of $\mathrm{M}^{\mathrm{a}}$ Céu Lamas (Hospital Magalhães Lemos) on the blood sample collection.

\section{References}

Ambudkar SV, Dey S, Hrycyna CA, et al. (1999) Biochemical, cellular, and pharmacological aspects of the multidrug transporter. Annu Rev Pharmacol Toxicol 39:361-398.

Ameyaw MM, Regateiro F, Li T, et al. (2001) MDR1 pharmacogenetics: frequency of the C3435T mutation in exon 26 is significantly influenced by ethnicity. Pharmacogenetics 11:217-221.

Bebawy M, Chetty M (2009). Gender differences in p-glycoprotein expression and function: effects on drug disposition and outcome. Curr Drug Metab 10:322-328.

Becker ML, Visser LE, van Schaik RH, et al. (2009) Common genetic variation in the $\mathrm{ABCB} 1$ gene is associated with the cholesterol-lowering effect of simvastatin in males. Pharmacogenomics 10:1743-1751.

Bernal ML, Sinues B, Fanlo A, et al. (2003) Frequency distribution of C3435T mutation in exon 26 of the MDR1 gene in a Spanish population. Ther Drug Monit 25:107-111.

Binder EB, Kunzel HE, Nickel T, et al. (2009) HPA-axis regulation at in-patient admission is associated with antidepressant therapy outcome in male but not in female depressed patients. Psychoneuroendocrinology 34:99-109.

Borst P, Elferink RO (2002) Mammalian ABC transporters in health and disease. Annu Rev Biochem 71:537-592.

Carvalho S (2012) Variáveis Sócio-Cognitivas como Preditores da Resposta ao Tratamento Farmacológico da Depressão. University of Coimbra, Coimbra.

Cascorbi I, Gerloff T, Johne A, et al. (2001) Frequency of single nucleotide polymorphisms in the P-glycoprotein drug transporter MDR1 gene in white subjects. Clin Pharmacol Ther 69:169-174.

Cavaco I, Gil JP, Gil-Berglund E, et al. (2003) CYP3A4 and MDR1 alleles in a Portuguese population. Clin Chem Lab Med 41:1345-1350.

Chowbay B, Cumaraswamy S, Cheung YB, et al. (2003) Genetic polymorphisms in MDR1 and CYP3A4 genes in Asians and the influence of MDR1 haplotypes on cyclosporin disposition in heart transplant recipients. Pharmacogenetics 13:89-95.
Compton WM, Conway KP, Stinson FS, et al. (2006) Changes in the prevalence of major depression and comorbid substance use disorders in the United States between 1991-1992 and 2001-2002. Am J Psychiatry 163:2141-2147.

Correia C, Santos P, Coutinho AM, et al. (2009) Characterization of pharmacogenetically relevant CYP2D6 and ABCB1 gene polymorphisms in a Portuguese population sample. Cell Biochem Funct 27:251-255.

Dong C, Wong ML, Licinio J (2009) Sequence variations of ABCB1, SLC6A2, SLC6A3, SLC6A4, CREB1, CRHR1 and NTRK2: association with major depression and antidepressant response in Mexican-Americans. Mol Psychiatr 14:1105-1118.

Estrela Rde C, Ribeiro FS, Barroso PF, et al. (2009) ABCB1 polymorphisms and the concentrations of lopinavir and ritonavir in blood, semen and saliva of HIV-infected men under antiretroviral therapy. Pharmacogenomics 10:311-318.

Fujii T, Ota M, Hori H, et al. (2012) Association between the functional polymorphism (C3435T) of the gene encoding Pglycoprotein $(A B C B 1)$ and major depressive disorder in the Japanese population. J Psychiatr Res 46:555-559.

Gumus-Akay G, Rustemoglu A, Karadag A, et al. (2008) Genotype and allele frequencies of MDR1 gene C1236T polymorphism in a Turkish population. Genet Mol Res 7:1193-1199.

Hodges LM, Markova SM, Chinn LW, et al. (2011) Very important pharmacogene summary: ABCB1 (MDR1, P-glycoprotein). Pharmacogenet Genomics 21:152-161.

Hoffmeyer S, Burk O, von Richter O, et al. (2000) Functional polymorphisms of the human multidrug-resistance gene: multiple sequence variations and correlation of one allele with P-glycoprotein expression and activity in vivo. Proc Natl Acad Sci U S A 97:3473-3478.

Holsboer F (2000) The corticosteroid receptor hypothesis of depression. Neuropsychopharmacology 23:477-501.

Jeannesson E, Albertini L, Siest G, et al. (2007) Determination of $\mathrm{ABCB} 1$ polymorphisms and haplotypes frequencies in a French population. Fundam Clin Pharmacol 21:411-418.

Kimchi-Sarfaty C, Marple AH, Shinar S, et al. (2007a). Ethnicityrelated polymorphisms and haplotypes in the human ABCB1 gene. Pharmacogenomics 8:29-39.

Kimchi-Sarfaty C, Oh JM, Kim IW, et al. (2007b). A "silent" polymorphism in the MDR1 gene changes substrate specificity. Science 315:525-528.

Kurita H, Maeshima H, Kida S, et al. (2012) Serum dehydroepiandrosterone (DHEA) and DHEA-sulfate (S) levels in medicated patients with major depressive disorder compared with controls. J Affect Disord 46:205-212.

Lee SS, Kim SY, Kim WY, et al. (2005) MDR1 genetic polymorphisms and comparison of MDR1 haplotype profiles in Korean and Vietnamese populations. Ther Drug Monit 27:531-535.

Leschziner GD, Andrew T, Pirmohamed M, et al. (2007) ABCB1 genotype and PGP expression, function and therapeutic drug response: a critical review and recommendations for future research. Pharmacogenomics J 7:154-179.

Muller MB, Keck ME, Binder EB, et al. (2003) ABCB1 (MDR1)type P-glycoproteins at the blood-brain barrier modulate the activity of the hypothalamic-pituitary-adrenocortical system: implications for affective disorder. Neuropsychopharmacology 28:1991-1999.

O'Brien FE, Dinan TG, Griffin BT, et al. (2012) Interactions between antidepressants and P-glycoprotein at the blood-brain barrier: clinical significance of in vitro and in vivo findings. Br J Pharmacol 165:289-312.

Onnie CM, Fisher SA, Pattni R, et al. (2006) Associations of allelic variants of the multidrug resistance gene (ABCB1 or MDR1) 
and inflammatory bowel disease and their effects on disease behavior: a case-control and meta-analysis study. Inflamm Bowel Dis 12:263-271.

Palmieri O, Latiano A, Valvano R, et al. (2005) Multidrug resistance 1 gene polymorphisms are not associated with inflammatory bowel disease and response to therapy in Italian patients. Aliment Pharmacol Ther 22:1129-1138.

Pariante CM, Miller AH (2001) Glucocorticoid receptors in major depression: relevance to pathophysiology and treatment. Biol Psychiatr 49:391-404.

Pechandova K, Buzkova H, Slanar O, et al. (2006) Polymorphisms of the MDR1 gene in the Czech population. Folia Biol (Praha) 52:184-189.

Potocnik U, Ferkolj I, Glavac D, et al. (2004) Polymorphisms in multidrug resistance 1 (MDR1) gene are associated with refractory Crohn disease and ulcerative colitis. Genes Immun 5:530-539.

Qian W, Homma M, Itagaki F, et al. (2006) MDR1 gene polymorphism in Japanese patients with schizophrenia and mood disorders including depression. Biol Pharm Bull 29:2446-2450.

Salama NN, Yang Z, Bui T, et al. (2006) MDR1 haplotypes significantly minimize intracellular uptake and transcellular P-gp substrate transport in recombinant LLC-PK1 cells. J Pharm Sci 95:2293-2308.

Sapmaz A, Ozen Karatayli SC, Dagli U et al. (2008) Effects of polymorphism in G2677T/A triallelic region of MDR1 gene in Turkish patients with inflammatory bowel disease. Turk J Gastroenterol 19:168-173.

Schaich M, Kestel L, Pfirrmann M, et al. (2009) A MDR1 (ABCB1) gene single nucleotide polymorphism predicts outcome of temozolomide treatment in glioblastoma patients. Ann Oncol 20:175-181.

Sipeky C, Csongei V, Jaromi L, et al. (2011) Genetic variability and haplotype profile of MDR1 (ABCB1) in Roma and Hungarian population samples with a review of the literature. Drug Metab Pharmacokinet 26:206-215.

Solomon MB, Furay AR, Jones K, et al. (2012) Deletion of forebrain glucocorticoid receptors impairs neuroendocrine stress responses and induces depression-like behavior in males but not females. Neuroscience 203:135-143.

Suzuki T, Zhao YL, Nadai M, et al. (2006) Gender-related differences in expression and function of hepatic P-glycoprotein and multidrug resistance-associated protein (Mrp2) in rats. Life Sci 79:455-461.

Tan EK, Chan DK, Ng PW, et al. (2005) Effect of MDR1 haplotype on risk of Parkinson disease. Arch Neurol 62:460-464.

Tan EK, Drozdzik M, Bialecka M et al. (2004) Analysis of MDR1 haplotypes in Parkinson's disease in a white population. Neurosci Lett 372:240-244.

Uhr M, Holsboer F, Muller MB (2002) Penetration of endogenous steroid hormones corticosterone, cortisol, aldosterone and progesterone into the brain is enhanced in mice deficient for both mdr1a and mdr1b P-glycoproteins. J Neuroendocrinol 14:753-759.

Unschuld PG, Ising M, Roeske D, et al. (2010) Gender-specific association of galanin polymorphisms with HPA-axis dysregulation, symptom severity, and antidepressant treatment response. Neuropsychopharmacology 35:1583-1592.

Yau JL, Noble J, Thomas S, et al. (2007) The antidepressant desipramine requires the ABCB1 (Mdr1)-type p-glycoprotein to upregulate the glucocorticoid receptor in mice. Neuropsychopharmacology 32:2520-2529.

Zhang YT, Yang LP, Shao H, et al. (2008) ABCB1 polymorphisms may have a minor effect on ciclosporin blood concentrations in myasthenia gravis patients. Br J Clin Pharmacol 66:240-246. 